\title{
The Reason and Coping Measures of Employees' Resistance to Information System
}

\author{
Chunhua Xiao \\ Department of Corporate Management, Management School, Jinan University, Guangzhou, China \\ Email:xchflora@163.com
}

How to cite this paper: Xiao, C.H. (2017) The Reason and Coping Measures of Employees' Resistance to Information System. Journal of Human Resource and Sustainability Studies, 5, 87-93. https://doi.org/10.4236/jhrss.2017.51009

Received: February 17, 2017

Accepted: March 27, 2017

Published: March 30, 2017

Copyright $\odot 2017$ by author and Scientific Research Publishing Inc. This work is licensed under the Creative Commons Attribution International License (CC BY 4.0).

http://creativecommons.org/licenses/by/4.0/

\begin{abstract}
The management of employee resistance is an important aspect of information system implementation, the resistance of employees relates to successfully implement systems or not. In our research, we first defined information system resistance, and analyzed the reasons of systems resistance from systems, organizations, as well as personal perspectives. Based on this, we then propose the appropriate human resources management proposals, eventually matching the various elements in human resources management, improving the success possibility of system implementation.
\end{abstract}

\section{Keywords}

Information System, Resistance, Element Fit in Human Resource

Management

\section{Introduction}

In order to improve the performance, quantities of corporations set out to introduce information systems from the eighties and nineties of the last century. Unfortunately, the failure rate was as high as $70 \%$ or $80 \%$. Scholars did research trying to make sense of the problems during different processes of information systems implementation. In all factors that cause the system failing, the resistance to information system is one of the most important reasons [1]. In this article, we focus on user resistance after information system implementation, analyses the reasons causing the resistance and propose appropriate human resource management solutions. In the following sections, first of all, we make a definition of resistance and make sense of the reasons of user resistance. Then we conclude the factors in user resistance from the perspectives of organization and individual. In the third part, we put forward the coping measures of employee measures. In the last part, we make a conclusion. 


\section{The Definition of User Resistance and Its Reasons}

After information system implementation, the definition of user resistance can explain in its forms and causes: on one hand, from the perspective of form, user resistance can perform in sensible or latent action; on the other hand, the resistance action reflects passive action when users are afraid of the changes in job content, power, which cause by information systems implementation [2].

\subsection{The Resistance Behavior of Employees}

The topic of resistance is being widely discusses during the researches of information systems. But researchers hold different opinions. Markus (1983) suggested that resistance is adverse reaction which hinders the expected target [3]. Lapointe and Rivard (2005) had proposed model of resistance, in the model, they point out that resistance of information systems can divide into five dimensions, saying that initial conditions, resistance subject, behavior objects, perceived threats, and resistance behavior [4]. All the definition agreed that resistance is a behavior, including the implicit and sensible behavior. Here we define resistance as a negative behavior or mental state, which show negative influence on organization.

First of all, for the moment researches concerning user resistance, researchers study the topic is mainly based on the theories such as status quo bias theory, human-systems interaction theory, people-oriented theory. Whatever the theory is, we can analyze the subjects who resist, the behavior of employee resistance, the purpose of resistance, the causing effects of resistance [1]. When an employee is aware of the system causing their own interests reducing, or when the benefit is inferior to the moment that before the information systems implementation, or when employees perceive that the income is not equal to endeavour, or when they feel the implementation of system is a problem for them, they will resist the information system implementation. At the beginning, employee resistance behavior is in a violent action. Resistance can divide into indifference, passive resistance, active resistance as well as attacks according to their level [4]. Varying degrees of resistance cause different damage. Therefore, the management of users in companies, in other words, the employees, is a very important issue during the process of system implementation.

\subsection{Reasons of Employees' Resistance}

The behavior of resistance may come from the change in various aspects. In essence, we can analyze from the perspectives of systems, organizations, and individuals.

\subsubsection{System Factors in Resistance Behavior}

In order to minimize costs and facility the later update, generally, many systems including ERP and CRM system are standardized unless the enterprise has special requirements in system design [5]. In the condition such as system compatibility emerging the problem, the system failing to maximize efficiency, em- 
ployees tend to resist the systems. Systems decision theory believes that each system may be accepted or rejected due to its design features, which is closely related to its own design. But in reality most systems are purchased from specialized software manufacturers, software manufacturers can't take every user's demand into consideration, thus causing the user resistance.

In addition, system decision theory also believes that except the system interface problem, the problems in perspectives such as system functionality, security, convenience and concentration will also cause user resistance. Employees need to be evaluated during work process, when the problem in systems causing their efficiency and effectiveness decline, the assessment of employees will be unsatisfactory [6]. But in reality most enterprise assess employees based on results, employees may get lower revenues because of system problems though paying the same effort.

Some scholars put forward that the increasing workload which causing by the system implementation, is another important reason of system resistance. Employees need to acquire the relevant skills to make use of systems effectively, and attain their work requirements apart from their working hours.

In short, if the system is not customized, the system may cause employees to resist during the process of implementation due to the problem in itself. Although it may be temporary, but it will take time for employees to adapt with the system.

\subsubsection{Organization Factors in Resistance Behavior}

Firstly, the culture in the organization may be a reason leading resistance from employees in the system, the cultural resistance comes from the difference between the companies use the system and design the system, organizational culture and the culture which carried by systems inconsistencies can lead to system resistance. In this context, organizational culture and the culture of system needs time to adapt, the system resistance is one of the result of two cultures collide.

Kim and Kankanhalli [1] put forward that organizational support for change is another reason for employees to resist. Organizations support refers to organizations provide the facilitation to allow users better adapt to changes due to information systems implementation. Change the way of work needs to guide and related resources, and organization provide a series of support such as training and the related resources to effect organizational change. Along with organizational support for the changes increased, employees will present less negative reaction, the resistance during the system implementation will also reduce [8].

\subsubsection{Individual Factors in Resistance Behavior}

First of all, the ability of employees' stress tolerance will affect the system's resistance, system implementation can lead to the need to change their jobs. After system implementation, the expected output can't be get immediately, but turn to the stage of adjustment. During the adjustment stage, employees need to bear the pressure of psychological and enterprise. On one hand, system led to change in original work, originally the skilled work occurred changes, employee began to suspect his own ability. On the other hand, the input of energy and time can't 
get the expected results, influence work assessment, even the risk of lost work.

System implementation have influence on the original module, and bring change in work in a row. System makes the work into modular, and standardize, in order to improve efficiency. However, this also leads to the increasing of employee's switching costs. Switching cost refers to the employees feel useless when they turn from the status quo to the new system. Switching cost includes uncertainty cost and sunk costs. Uncertainty cost means in a condition that feel unconfidently on his own ability to make decision. Sunk costs means you have to abandon past efforts due to the change.

System implementation will also allow the employees feel challenge of position in the group, system changes the position of employees: the employees who master the system quickly become the new focus, challenge the original employees who in the center of social network. To those who are in the original position, the implemented system makes them in challenge.

Therefore, the system lead to increasing in psychological pressure, social status is challenged and switching costs increased, thus leading employees to resist the implementation of systems.

Resistance may be formed in several reasons, saying that the systems, organizations or personal reasons. To solve this problem, we focus on organizations and individuals to explore solutions.

\section{The Coping Measures to System Resistance}

In the context of information systems implementation, I think the key lies in matching elements in human resources to cope with resistance. And there exists four matching in human resource: matching person with position; matching person with person; matching position with position; matching pay with performance. Next, we will explain how to match each part to eliminate the problems in the management of information systems.

\subsection{Matching Person with Position}

The matching between person and position refers to the characteristics in human should match the characteristics of the implemented system. Once mismatch, you will find that the resistance from employees is easy to occur. The mismatch between person and position come from two possible causes. On one hand, the introduction of information system changed the behavior of employees to a large extent, while before in-depth training, employees are hard to use the system to achieve the desired effect, thus leading to resistance; on the other hand, employees have difficulty in meeting the system requirements.

Based on the above two causes of resistance, we use different ways to evade. If employees can't meet the system requirements for their own literacy issues, we can solve the problem by job analysis and recruitment.

Job analysis [9] is a process in which he need make sense the skill, responsibility and knowledge to complete the work. Job analysis is an important and common human resource management technique. It is the cornerstone of all human 
resource management activities, and for other human resource management practices, such as selection, training, performance evaluation, salary, gather information. Job analysis differs from the job description and work processes, it not only need to consider the employee's job responsibilities and job definition, but also needs to take the company's strategy into consideration. Many enterprises especially SMEs in started stage don't implement information system, and systems are implemented when enterprises developed into track or its scale expanded. As a result, human resources planning who must to have strategy vision, we should not only have knowledge of job requirement in the future, but also clear awareness on enterprise development. Based on this, we conduct job analysis and recruit.

Recruitment serves as an important source to store human capital in enterprise, the result of recruitment affect the development of enterprises. Successful recruitment is the catalyst in enterprise development, the failure of recruitment will bring immeasurable losses to the enterprise [10]. Talented person is essential for enterprise, and recruitment is the starting point of communication between employees and enterprises. For enterprises, they deliver their requirements to the candidate, and the candidates put their requirements and fit with enterprise requirement. In addition, during the recruitment process, the identification of talents is very important, the suitable talent guarantee the fit between the employees and positions.

Training is essential for the matching between person and position, the role of training is not just for employees to acquire more skills. In the context of system implementation, training can speed up the employees fit with the system, meanwhile speed up the operation of the system. Because of the system implementation, the tasks and working scope of employees are subjected to huge impact, so proper training helps employees quickly fit the implemented system.

\subsection{Matching Person with Person}

Anyone is embedded in certain social relations, so are the employees in organization. Trust based on the core of social network, social networks can be used as the enterprise's social capital. The social networks in enterprise can divide into the internal social network and external social networks. Internal social network means the relationship between the employees and organization, or the relationship between employee and employee. In this article, our main perspective is based on the internal social network, especially, the relationship between employee and employee. There is no doubt that social network exists in employees and social network help to promote business capabilities. When informal social networks can help people solve practical problems, employee satisfaction will raise, thus resistance of the system will decrease [11].

While in the organization, advice network is another network to help employees to solve the problem. To promote development of the advice network, the human resources department has the responsibility to coordinate and promote the relations between employees. As a result, a good organizational climate 
is required, and training is an important channel for developing good organizational climate. Regular reunion activities are beneficial to reinforce the relationship among employees.

In addition, in the implementation of information system, one of the principles in matching between person and person is the definition of the right of the employee, and it requires job analysis in the human resource module. Known as the cornerstone of human resources management, job analysis, which defines the position and the relationship between the positions, at the same time, it defines technical, knowledge, ability and responsibility which the employees should be met. Job analysis can descript the position in detail, make clear the principles in employees [12].

\subsection{Matching Position with Position}

The definition between tasks is important during job design. Job design is the starting point for goal setting and parameters selection, involving an important principle which matches job characteristics with those of employees, clarifying the important goal in work, in order to achieve win-win results [12]. Information system implementation has changed the jobs of employees to a large extent, whether tasks or the scope of work, which break the cycle of original sound work. Before establishing a new healthy circulatory system, the work of employees' is in a mess, which shows a direct result on employee perceptions of their work, leading to a resistance of new systems.

Eliminating the resistance to the newly implemented system, in addition to communicating with the system designers during the design process, we can also make human resource measures to reconcile the conflict between the jobs with the original one. Confronting with the changes in work, employees face pressure from themselves and the organization. In such a situation, training is an important measure. On one hand, training in employees let them complete their work, on the other hand, training do help in developing the potential [12]. For the enterprises which have implemented information system, training in employees can balance the cognition of employees on their job and keep a good attitude. Meanwhile, training plays an important role in updating their knowledge, and using new knowledge to deal with changes.

\subsection{Matching Pay with Performance}

Besides pursuit success in their career, employees also expect get proper compensation from the organization. When employees find that they utilize the information systems during their work but the information systems can't help them get a higher pay. In this time, the change in pay and tasks of employees is consistency, the material changes can balance employees' psychological changes which caused by job change.

On one hand, the matching between pay and performance will make the employees sensing that their efforts in using information systems will pay back. On the other hand, they will persist in and make better use of the information sys- 
tems. In this case, the matching between pay and performance can relieve the anxiety of employees in the process of using a new technology.

\section{Conclusion}

Resistance to the system is a problem which is difficult to avoid during the process of implementing. For enterprises, it is not only an opportunity, but also a challenge. During the process of eliminating system resistance, the managers can improve their management level, as well as to promote cohesion among employees. Therefore, the treating on resistance of information systems shows practical significance to a degree. But at the same time, we just in the article provide several aspects of human resource management employees' resistance, and in this article there is no empirical evidence, therefore further empirical research and operational recommendations are needed.

\section{References}

[1] Kim, H. and Kankanhalli, A. (2009) Investigating User Resistance to Information Systems Implementation: A Status Quo Bias Perspective. MIS Quarterly, 33, 567-582.

[2] Zhou, R. (2013) The Reasons of IT Resistance and Its Management Countermeasures. Journal of Commercial Economics, 2, 45-47.

[3] Markus, M.L. (1983) Power, Politics, and MIS Implementation. Communications of the ACM, 26, 430-444. https://doi.org/10.1145/358141.358148

[4] Lapointe, L. and Rivard, S.A. (2005) Multilevel Model of Resistance to Information Technology Implementation. MIS Quarterly, 29, 461-491.

[5] Klaus, H., Rosemann, M. and Gable, G. (2000) What Is ERP? Information Systems Frontiers, 2, 141-162. https://doi.org/10.1023/A:1026543906354

[6] Klaus, T. and Blanton, J.E. (2010) User Resistance Determinants and the Psychological Contract in Enterprise System Implementations. European Journal of Information Systems, 19, 625-636. https://doi.org/10.1057/ejis.2010.39

[7] Gobbin, R. (1998) The Role of Cultural Fitness in User Resistance to Information Technology Tools. Interacting with Computers, 9, 275-285. https://doi.org/10.1016/S0953-5438(97)00031-3

[8] Hirschheim, R. and Newman, M. (1988) Information Systems and User Resistance: Theory and Practice. The Computer Journal, 31, 398-408. https://doi.org/10.1093/comjnl/31.5.398

[9] Zhang, L. (2002) Job Analysis: The Cornerstone of Enterprise Human Resource. Human Resources Development of China, 10, 43-45.

[10] Sykes, T.A., Venkatesh, V. and Johnson, J.L. (2014) Enterprise System Implementation and Employee Job Performance: Understanding the Role of Advice Networks. MIS Quarterly, 38, 51-54.

[11] Li, W. and Shi, K. (2006) The New Trend of Job Analysis Research. Advances in Psychological Science, 3, 418-425.

[12] $\mathrm{Hu}, \mathrm{N}$. (2010) Comparative Analysis of Enterprise Job Design Theory. Social Sciences in Hunan, 2, 106-110. 
Submit or recommend next manuscript to SCIRP and we will provide best service for you:

Accepting pre-submission inquiries through Email, Facebook, LinkedIn, Twitter, etc. A wide selection of journals (inclusive of 9 subjects, more than 200 journals)

Providing 24-hour high-quality service

User-friendly online submission system

Fair and swift peer-review system

Efficient typesetting and proofreading procedure

Display of the result of downloads and visits, as well as the number of cited articles Maximum dissemination of your research work

Submit your manuscript at: http://papersubmission.scirp.org/

Or contact jhrss@scirp.org 